\title{
Keyhole pattern for preoperative marking for reduction mammaplasty
}

\author{
Marcus Vinícius Jardini Barbosa MD PhD ${ }^{1}$, Fábio Xerfan Nahas MD PhD ${ }^{1}$, \\ Miguel Angelo Sabia Neto MD², Lydia Masako Ferreira MD PhD ${ }^{1}$
}

\begin{abstract}
MVJ Barbosa, FX Nahas, MAS Neto, LM Ferreira. Keyhole pattern for preoperative marking for reduction mammaplasty. Can J Plast Surg 2010;18(4):130-134.
\end{abstract}

BACKGROUND: There are many techniques used for reduction mammaplasty; however, the most frequently performed procedures result in an inverted T scar. Preoperative marking is an important step for the success of the procedure, especially for surgeons at the initial learning stage. However, there is no consensus regarding the best method. In 1981, Strömbeck designed a pattern for preoperative marking for reduction mammaplasty. This pattern provides stable parameters that promotes an acceptable symmetry marking.

OBJECTIVE: To evaluate the use of the Strömbeck pattern for preoperative marking for reduction mammaplasty.

METHODS: Fifty-seven patients who underwent reduction mammaplasty between April 2006 and April 2007 were prospectively evaluated. Patient ages ranged from 17 to 61 years; the mean body mass index was $22.2 \mathrm{~kg} / \mathrm{m}^{2}$. After defining the standard landmarks of the breast, preoperative markings were made using the Strömbeck pattern. Breast reduction surgery was performed under local anesthesia with sedation. Postoperative results were evaluated according to a numerical visual analogue scale, at the seven-, 15 . and 30-day follow-up periods. The Student's $t$ test and the Kruskal-Wallis test were used for statistical analysis $(\mathrm{P}<0.05)$.

RESULTS: The mean weight of resected breast tissue was $317.5 \mathrm{~g}$ for the right breast and $305.8 \mathrm{~g}$ for the left breast $(\mathrm{P}=0.17)$. Scores obtained using a visual analogue scale showed a progressive increase in the scores during the postoperative follow-up period $(\mathrm{P}<0.0001)$.

CONCLUSION: The use of the Strömbeck pattern enabled surgeons to perform reduction mammaplasty with good postoperative results as seen in the follow-up periods.

\section{Un diagramme en trou de serrure comme marquage préopératoire de réduction mammaire}

HISTORIQUE : Il existe de nombreuses techniques de réduction mammaire, mais les plus utilisées produisent une cicatrice en $\mathrm{T}$ inversé. Le marquage préopératoire constitue une étape importante pour assurer la réussite de l'intervention, notamment chez les chirurgiens aux premières étapes d'apprentissage. Il n'existe toutefois pas de consensus quant à la meilleure méthode à utiliser. En 1981, Strömbeck a conçu une technique de marquage préopératoire en prévision d'une réduction mammaire, laquelle fournit des paramètres stables favorisant un marquage symétrique acceptable.

OBJECTIF : Évaluer l'utilisation de la technique de marquage préopératoire de Strömbeck en prévision d'une réduction mammaire.

MÉTHODOLOGIE : Cinquante-sept patientes qui ont subi une réduction mammaire entre avril 2006 et avril 2007 ont subi une évaluation prospective. Elles avaient de 17 à 61 ans et un indice de masse corporelle moyen de $22,2 \mathrm{~kg} / \mathrm{m}^{2}$. Après avoir défini les repères anatomiques standards du sein, les chercheurs ont effectué le marquage préopératoire conformément à la technique de Strömbeck. Ils ont procédé à la réduction mammaire sous anesthésie locale accompagnée de sédation. Ils ont évalué les résultats postopératoires d'après une échelle analogique numérique visuelle, lors du $7^{\mathrm{e}}$, du $15^{\mathrm{e}}$ et du $30^{\mathrm{e}}$ jour de suivi. Le test $t$ de Student et le test de Kruskal-Wallis ont inspiré l'analyse statistique $(\mathrm{P}<0,05)$.

RÉSULTATS : Les tissus mammaires réséqués du sein droit pesaient en moyenne $317,5 \mathrm{~g}$, et ceux du sein gauche, 305,8 $\mathrm{g}(\mathrm{P}=0,17)$. Les indices obtenus au moyen d'une échelle analogique visuelle révélaient une augmentation graduelle pendant la période de suivi postopératoire $(\mathrm{P}<0,0001)$.

CONCLUSION : L'utilisation de la technique de Strömbeck a permis aux chirurgiens de procéder à une réduction mammaire donnant de bons résultats postopératoires, tels que l'a démontré le suivi.

Key Words: Breast; Breast surgery; Mammaplasty; Preoperative procedures

$\mathrm{T}$ here are many techniques described for reduction mammaplasty; however, the most frequently performed procedures result in an inverted $\mathrm{T}$ scar $(1,2)$. Because the breast is a paired structure, postoperative symmetry is an important surgical goal. Therefore, preoperative surgical planning and marking are important steps for the success of the procedure, mainly for surgeons at the initial learning stage $(3,4)$. There is no consensus regarding the best method for preoperative marking. Some authors advocate free-hand preoperative marking, but it requires experience and practice to avoid postoperative asymmetries (3). Others have used rulers and patterns, such as the wire keyhole pattern, to prevent asymmetries (4). The Strömbeck pattern was initially designed for preoperative marking of the classic technique for reduction mammaplasty (5). This pattern provides stable predetermined parameters that promote an acceptable symmetry marking of the breast. The design of this pattern is obtained by transferring the marking parameters over an $\mathrm{x}$-ray film, which is easily adapted over any breast surface. Its use is very simple and can be applied to any reduction mammaplasty techniques that result in an inverted $\mathrm{T}$ scar (5).

The purpose of the present study was to evaluate the use of the Strömbeck pattern for preoperative surgical marking for reduction mammaplasty, with the superior pedicle technique associated with an inferiorly based dermoglandular flap.

\section{METHODS}

The present study was approved by the research ethics committee of the Federal University of São Paulo (São Paulo, Brazil), and all of the patients gave informed consent. Fifty-seven consecutive patients who underwent reduction mammaplasty at the São Paulo Hospital - Federal University of São Paulo, between April 2006 and April 2007, were prospectively evaluated. Mammary hypertrophy and ptosis were classified according to

${ }^{1}$ Division of Plastic Surgery, Federal University of São Paulo; ${ }^{2}$ Regional Hospital of Franca, São Paulo, Brazil

Correspondence: Dr Marcus Vinícius Jardini Barbosa, Division of Plastic Surgery, Federal University of São Paulo, Alameda Santos, 687, AP 133

Sao Paulo 01419-001, Brazil. Telephone/fax 55-16-3722-2329, e-mail drmbarbosa@gmail.com 
TABLE 1

Classification of breast ptosis and mammary hypertrophy in the study patients $(n=57)$

\begin{tabular}{lccc}
\hline & 1st degree & 2nd degree & 3rd degree \\
\hline Breast ptosis* $^{*}$ & $4(7)$ & $9(16)$ & $44(77)$ \\
$\begin{array}{l}\text { Mammary } \\
\text { hypertrophy }\end{array}$ & $27(47)$ & $19(33)$ & $11(20)$ \\
\hline
\end{tabular}

Data presented as $n$ (\%). *Regnault's classification (6); ${ }^{\dagger}$ Franco and Rebello's classification (7)

Regnault's (6) and Franco and Rebello's (7) classifications (Table 1). Patient ages ranged from 17 to 61 years (average age was 37 years); the average body mass index was $22.2 \mathrm{~kg} / \mathrm{m}^{2}$.

\section{Preoperative marking}

With the patient in the sitting position, the midline, midclavicular point, inframammary fold and the breast meridian (a line drawn from the midclavicular point to the nipple-areola complex [NAC]) were initially marked. The superior limit of the new position of the NAC (point A) was marked on the breast meridian using the anterior projection of the inframammary fold as a reference. The Strömbeck pattern was positioned at point $\mathrm{A}$ (Figures $1 \mathrm{~A}$ and $1 \mathrm{~B}$ ). The neoposition of the NAC and the skin excess between the lateral and medial limbs of the pattern were marked. From the pattern's lower extremities and with the patient supine, lines were marked medially and laterally toward the inframammary fold according to the skin excess estimated by bimanual manoeuvre (Figures 2A and 2B).

\section{Operative technique}

With the patient in a $30^{\circ}$ supine position and after sedation with intramuscular midazolan $(0.1 \mathrm{mg} / \mathrm{kg})$ and intravenous fentanyl $(1 \mu \mathrm{g} / \mathrm{kg})$, local anesthesia was administered with a fluid containing saline solution $(1000 \mathrm{~mL}), 1 \mathrm{~mL}$ of adrenaline $(1: 1,000,000)$ and lidocaine $(40 \mathrm{~mL}$ of a $2 \%$ solution $)$. The NAC was marked with a circular pattern $(5 \mathrm{~cm}$ in diameter). De-epithelialization of the skin between the previously marked

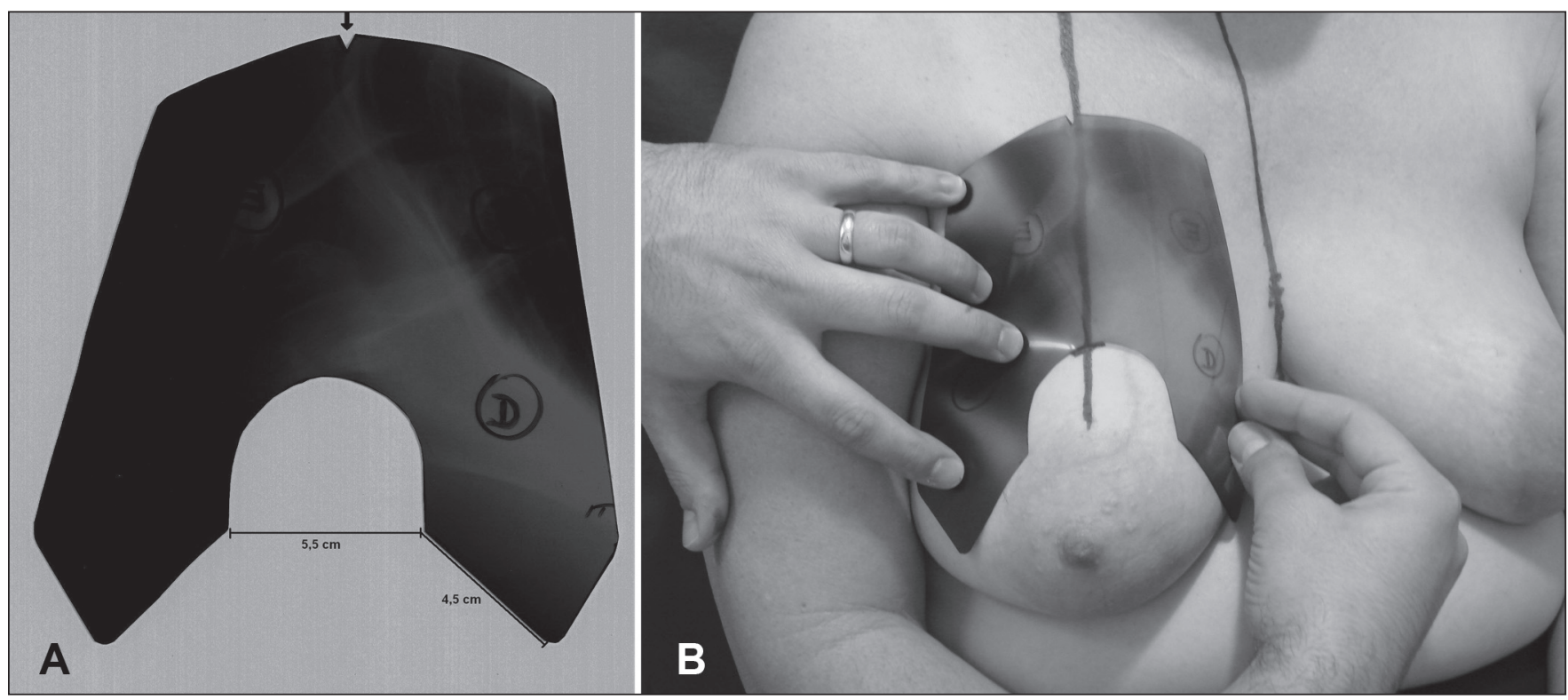

Figure 1) Preoperative breast marking with the Strömbeck pattern. A Strömbeck's pattern (the arrow indicates the superior sulcus that should be positioned on the breast meridian). B Positioning of the pattern on the breast (note the standard landmarks)
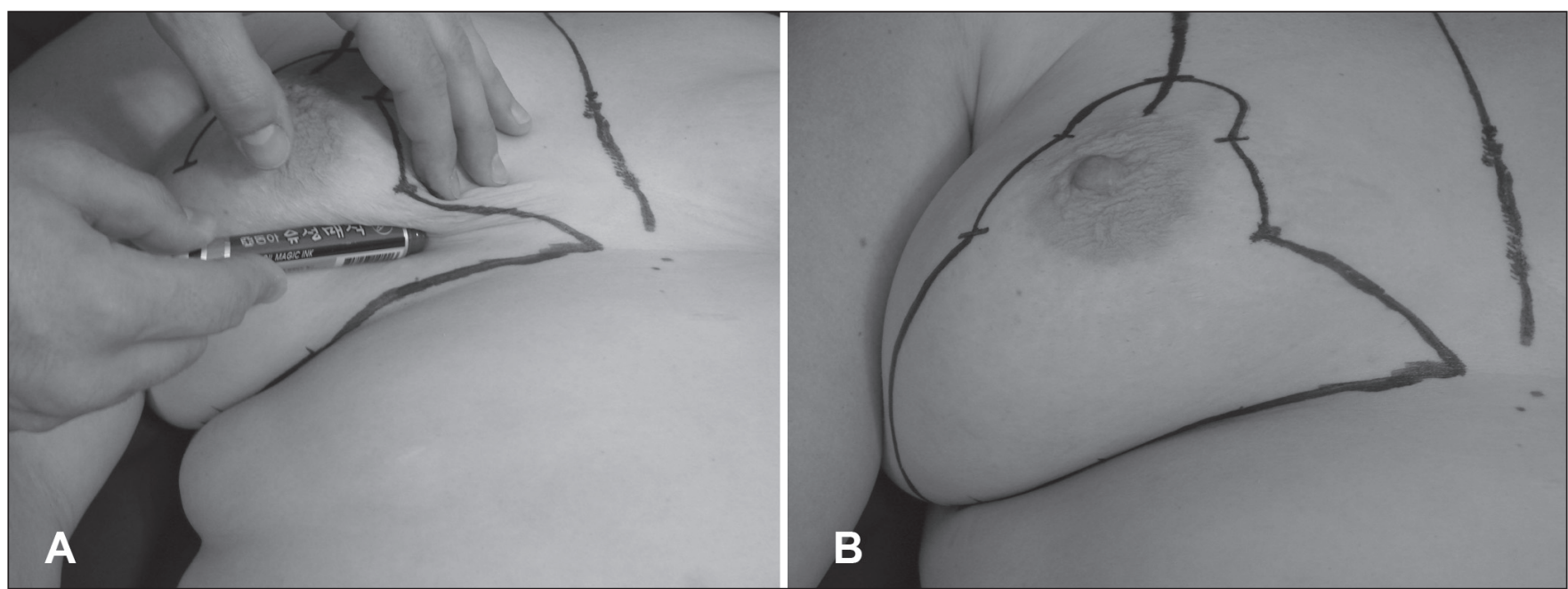

Figure 2) A Medial line marking the area of skin and glandular removal of the medial aspect of the breast. B Final preoperative marking of the area of skin and breast parenchyma to be removed 


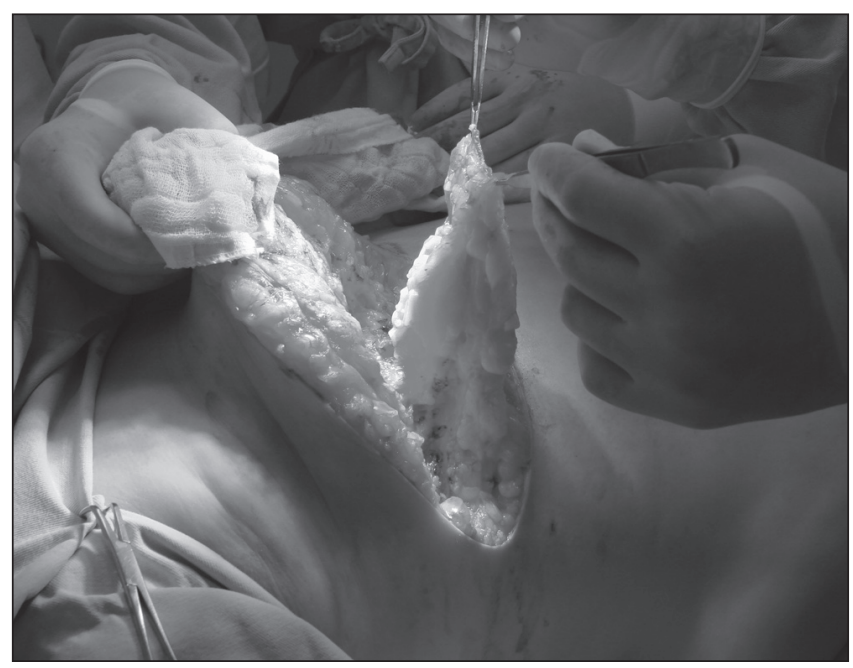

Figure 3) Surgical aspect of the inferiorly based dermoglandular flap

areas was performed, and the breast tissue was excised medially and laterally at the pattern's limb level. Breast tissue was excised beginning $1 \mathrm{~cm}$ below the inferior area of the NAC to create the superior pedicle. The excessive breast tissue was resected, leaving a central inferiorly based dermoglandular flap to fulfill the superior pole of the breast as described by Ribeiro (8). The extremities of this flap were superiorly fixed to the pectoralis fascia with a 2-0 nylon suture (Figure 3 ). The superior part of the NAC was placed in its new position (over the area previously de-epithelialized) using a 3-0 nylon suture. A U-shaped 3-0 nylon suture was used to close the superior corners of the medial and lateral skin flaps. The inferior edges of these flaps were sutured into the inframammary fold by a 3-0 nylon suture. The resulting vertical scar was sutured keeping a $4 \mathrm{~cm}$ to $5.5 \mathrm{~cm}$ length. Finally, the circular pattern was again used to mark the area of skin to be de-epithelialized for the new position of the NAC. Each layer of the vertical and inframammary incisions were closed with 4-0 nylon sutures, and the NAC was sutured to the breast skin with a 4-0 absorbable round-block suture.

Postoperative results (shape and symmetry) were evaluated by the patient according to a numerical visual analogue scale, graded from 0 (worst result) to 10 (best result), at the seven-, 15- and 30-day follow-up periods. The Student's $t$ test was used to compare the mass weight of the breast tissue resection, and the Kruskal-Wallis test was used to compare the scores obtained during the follow-up periods. $\mathrm{P}<0.05$ was considered to be statistically significant.

\section{RESULTS}

The mean weight of resected breast tissue was $317.5 \mathrm{~g}$ for the right breast and $305.8 \mathrm{~g}$ for the left breast $(\mathrm{P}=0.17)$. There were no significant differences when these values were compared (Student's $t$ test: $\mathrm{P}=0.17$ ). The length of the vertical scar ranged from $4 \mathrm{~cm}$ to $5.5 \mathrm{~cm}$ (mean length $4.7 \mathrm{~cm}$ ). There were no complications related to the anesthetic procedure. Early complications related to the surgery were epidermolysis of the lateral skin flap of the breast (two cases: $3.50 \%$ ) and ecchymosis (one case: $1.75 \%$ ) that were conservatively treated, resulting in good outcome within 10 postoperative days.
TABLE 2

Patient satisfaction scores using a numerical visual analogue scale (NVAS) at the three follow-up periods

\begin{tabular}{lccc}
\hline & \multicolumn{3}{c}{ Patients, $\mathbf{n}(\%)$} \\
\cline { 2 - 4 } NVAS scores & 7 th day & 15th day & 30th day \\
\hline 0 & - & - & - \\
1 & - & - & - \\
2 & - & - & - \\
3 & - & - & - \\
4 & - & - & - \\
5 & $11(19.30)$ & - & - \\
6 & $23(40.35)$ & - & - \\
7 & $23(40.35)$ & $28(49.12)$ & $1(1.75)$ \\
8 & - & $29(50.88)$ & $23(40.35)$ \\
9 & - & - & $28(49.12)$ \\
10 & - & - & $5(8.78)$ \\
Mean & $6.21^{*}$ & $7.50^{*}$ & $8.64^{*}$ \\
\hline
\end{tabular}

NVAS scores were graded from 0 (worst) to 10 (best) *Kruskal-Wallis test: $P<0.0001$

Scores obtained using a numerical visual analogue scale at the seven-, 15- and 30-day follow-up periods are presented in Table 2. These data showed a progressive increase in the scores across the postoperative period. There were significant differences when the scores obtained at the seven-day follow-up point were compared with those obtained at the 15- and 30-day follow-up points (Kruskal-Wallis test: $\mathrm{P}<0.0001$ ). In the same fashion, comparisons between the mean scores of the 15-day and 30-day follow-up periods showed significant differences (Kruskal-Wallis test: $\mathrm{P}<0.0001)$. The postoperative results of patients 2,32 and 51 are presented in Figures 4, 5 and 6.

\section{DISCUSSION}

Mammary hypertrophy and ptosis can be treated with many surgical techniques. These different techniques can lead to acceptable postoperative breast shape and symmetry $(3,9)$. Surgeons have asserted that the preferred surgical technique should be based on the plastic surgeon's experience. However, despite the great variability of techniques, the most used procedures for reduction mammaplasty still result in an inverted T scar (2).

Preoperative surgical planning includes breast marking, which is an important step to be observed (3). It determines both the amount of skin and breast tissue to be resected as well as breast symmetry (4). Surgical marking could be performed in different manners. Many plastic surgeons support free-hand marking because it does not involve rigid parameters (3). Others have used templates, rulers, goniometers and keyholeshaped patterns for preoperative marking. These devices are used to avoid postoperative asymmetry of the breasts, mainly during the learning stage $(4,10)$. In 1981, the Strömbeck pattern was introduced for surgical marking of the technique (5). This pattern permits plastic surgeons to perform all of the reduction mammaplasty techniques that normally would result in an inverted $\mathrm{T}$ scar (5).

In the present study, preoperative marking with the Strömbeck pattern enabled the surgeon to treat a great variability of mammary hypertrophy and ptosis by using the superior pedicle technique associated with an inferiorly dermoglandularbased flap (8). Three patients presented early complications during the follow-up period $(5.75 \%)$. These rates are similar to 


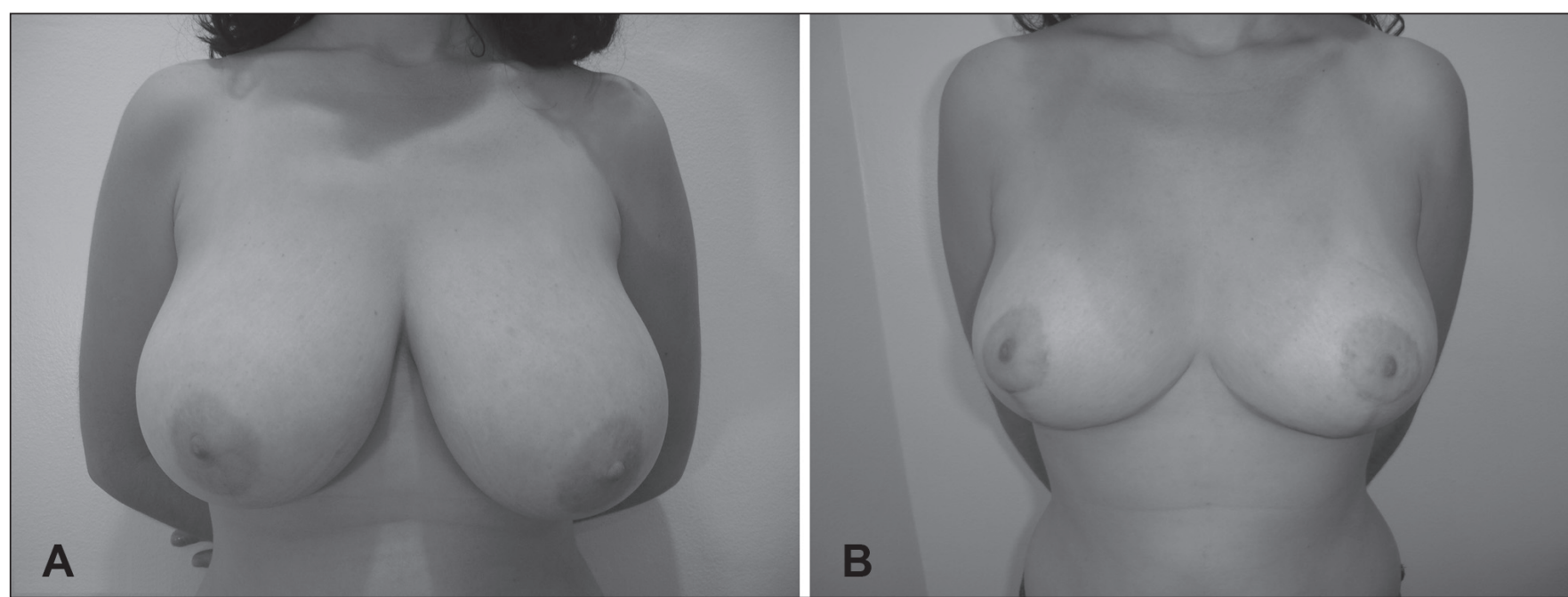

Figure 4) A 32-year-old Caucasian woman presenting with breast asymmetry and third-degree mammary hypertrophy with ptosis. A Preoperative frontal aspect. B 24 months postoperative view

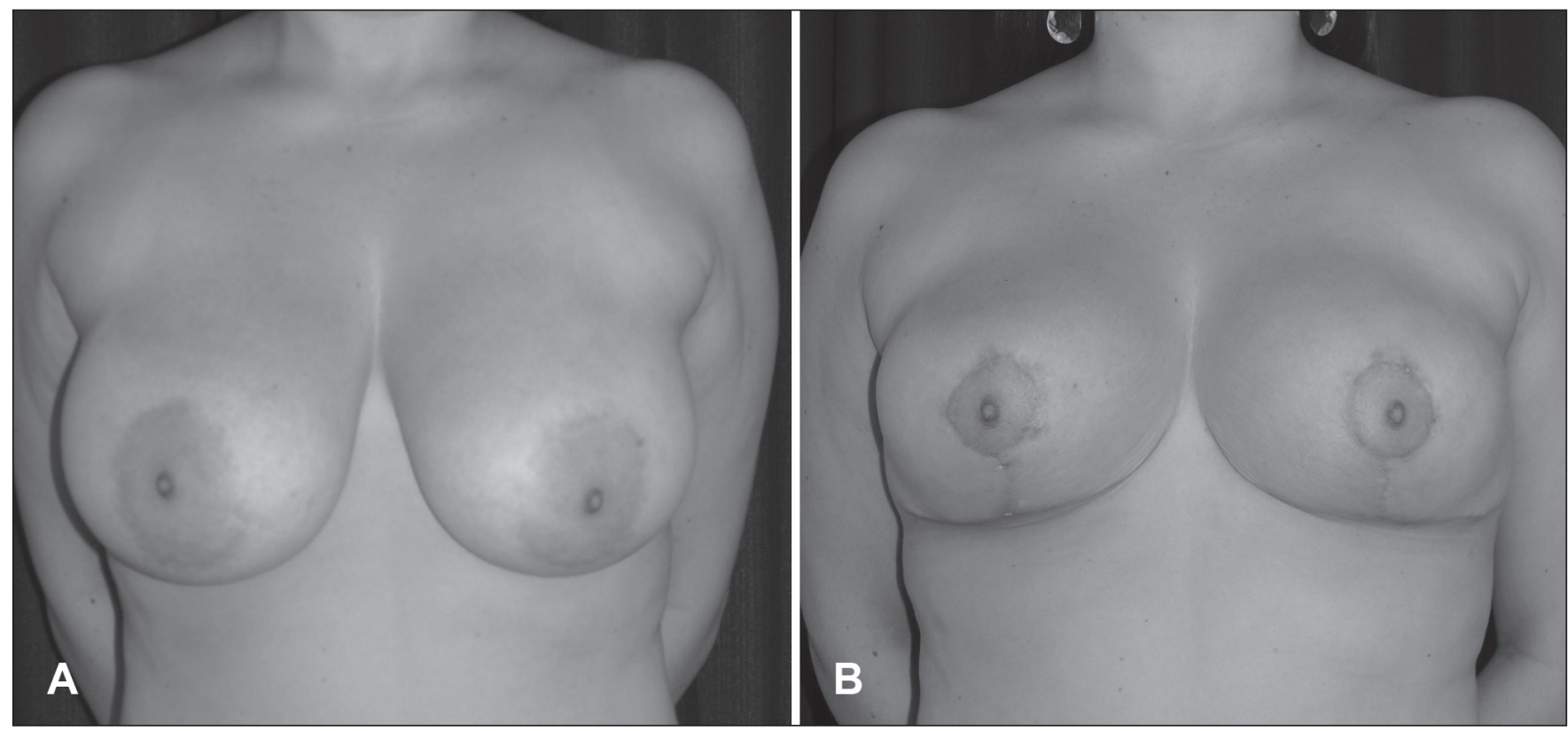

Figure 5) A 26-year-old Caucasian woman presenting with breast asymmetry and second-degree mammary hypertrophy with ptosis. A Preoperative frontal aspect. B 12 months postoperative view

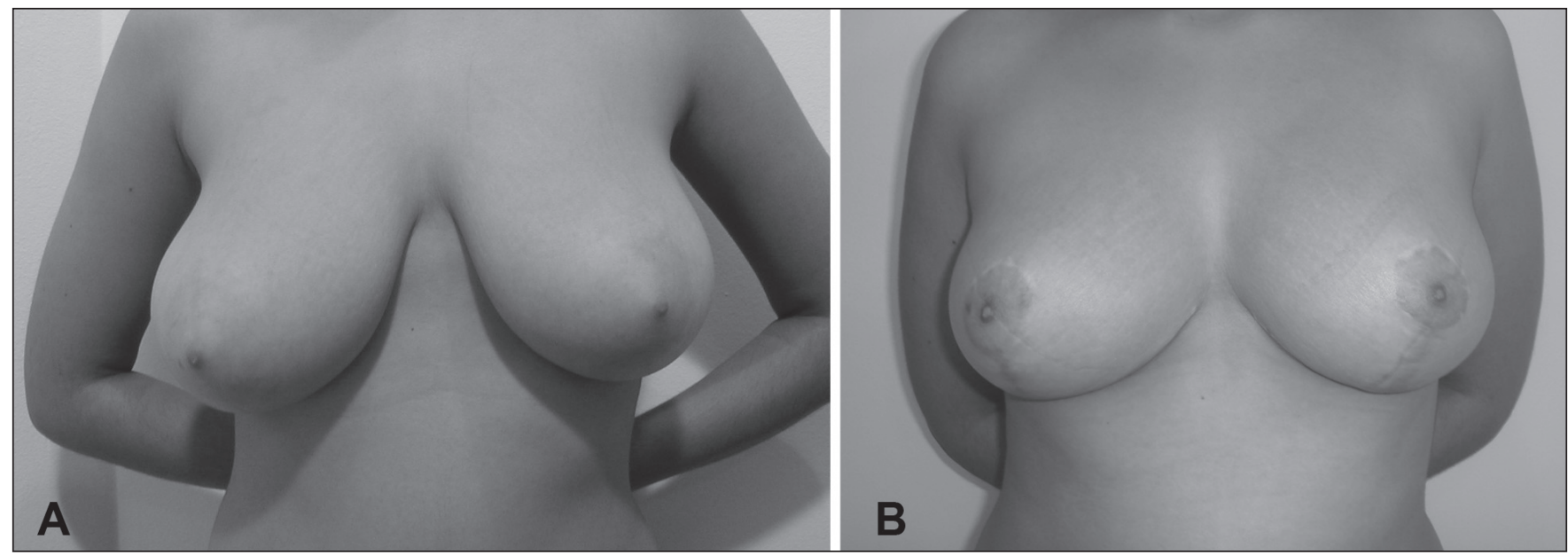

Figure 6) A 28-year-old Caucasian woman presenting with breast asymmetry and third-degree mammary hypertrophy with ptosis. A Preoperative frontal aspect. B 24 months postoperative view 
the literature findings $(10-12)$ and did not interfere with the postoperative results.

The visual analogue scale has been widely used for the evaluation of many surgery-related procedures including breast surgery $(9,12,13)$. The postoperative aspects of the breast were evaluated by the patients using a numerical visual analogue scale at the seven-, 15- and 30-day postoperative periods. Patients scored their own postoperative results according to the shape and symmetry of their breasts. These results presented a progressive increase in the scores during the follow-up period with significant differences when the periods were compared with one another (Kruskal-Wallis test: $\mathrm{P}<0.0001$ ). This progression probably occurred because the early postoperative period is characterized by the presence of surgical edema and recent scars, which become more discrete during the follow-up period. However, it is important to note that after the seven-day postoperative period, none of the scores were below 5 . These results showed that, in a relatively early postoperative period, patients were already satisfied with the surgical results regarding both shape and symmetry aspects.

\section{REFERENCES}

1. Akhtar S, Whitaker IS, Fourie, le R. A novel tension-reducing suture to protect the T-junction after reduction mammaplasty. Plast Reconstr Surg 2007;119:1386-7.

2. Chun YS, Lalonde DH, May JW Jr. Internal pedicle shaping to improve aesthetic results in reduction mammaplasty. Plast Reconstr Surg 2007;119:1183-9.

3. Fahmy FS, Hemington-Gorse SJ. The sitting, oblique, and supine marking technique for reduction mammaplasty and mastopexy. Plast Reconstr Surg 2006;117:2145-51.

4. Pülzl P, Schoeller T, Wechselberger G. Simplification of reduction mammaplasty using a specially designed ruler. Aesth Plast Surg 2006;30:622-4.

5. Strömbeck JO. Mamoplastia de reducción mediante resecciones glandulares bipolares. In: Goldwyn RM, ed. Cirugía plástica y de reconstrucción de la mama. Barcelona: Salvat Editores, 1981:181-93.

6. Regnault P. Breast reduction: B technique. Plast Reconstr Surg 1980;65:840.

7. Franco T, Rebello C. Mamaplastias. Cosmetic surgery. Rio de Janeiro: Atheneu, 1977:203.
As seen in the present study, the use of the Strömbeck pattern seems to be a good alternative for breast marking mainly because there is no need to memorize several reference points, except for the standard landmarks (midline, midclavicular point and inframammary fold). This pattern can be designed over flexible surfaces, such as an $\mathrm{x}$-ray film, which makes it adaptable to every breast surface and is easily reproducible. It is also possible to standardize surgical marking to achieve good breast symmetry, mainly for surgeons at the initial surgical learning stage.

\section{CONCLUSION}

The use of the Strömbeck pattern enabled surgeons to perform reduction mammaplasty using the superior pedicle technique associated with an inferiorly dermoglandular-based flap in patients who presented with a wide variability of mammary hypertrophy and ptosis. Patients experienced good postoperative results as demonstrated by breast shape and symmetry in the follow-up periods.

8. Ribeiro L. A new technique for reduction mammaplasty. Plast Reconstr Surg 1975;330-4.

9. Freire M, Neto MS, Garcia EB, Quaresma MR, Ferreira LM. Functional capacity and postural pain outcomes after reduction mammaplasty. Plast Reconstr Surg 2007;119:1149-56.

10. Lista F, Ahmad J. Vertical scar reduction mammaplasty: A 15-year experience including a review of 250 consecutive cases. Plast Reconstr Surg 2006;117:2152-65.

11. Atterhem H, Holmner S, Janson PE. Reduction mammaplasty: Symptoms, complications, and late results. A retrospective study on 242 patients. Scand J Plast Reconstr Surg Hand Surg 1998;32:281-6.

12. Persichetti P, Cagli B, Tenna S, Simone P, Marangi GF, Li Vecchi G. Decision making in the treatment of tuberous and tubular breasts: Volume adjustment as a crucial stage in the surgical strategy. Aesth Plast Surg 2005;29:482-8.

13. Nahas FX, Solia D, Ferreira LM, Novo NF. The use of tissue adhesive for skin closure in body contouring surgery. Aesth Plast Surg 2004;28:165-9. 